\title{
Compliance with haemodialysis practice guidelines in Egypt
}

A.M.A. Ahmed, ${ }^{7}$ M.F. Allam, ${ }^{2}$ E.S. Habil, ${ }^{2}$ A.M. Metwally, ${ }^{7}$ N.A. Ibrahiem, ${ }^{7}$ M. Radwan, ${ }^{2}$ M.M. El-Gaafary ${ }^{2}$ and M.A. Gadallah $^{2}$

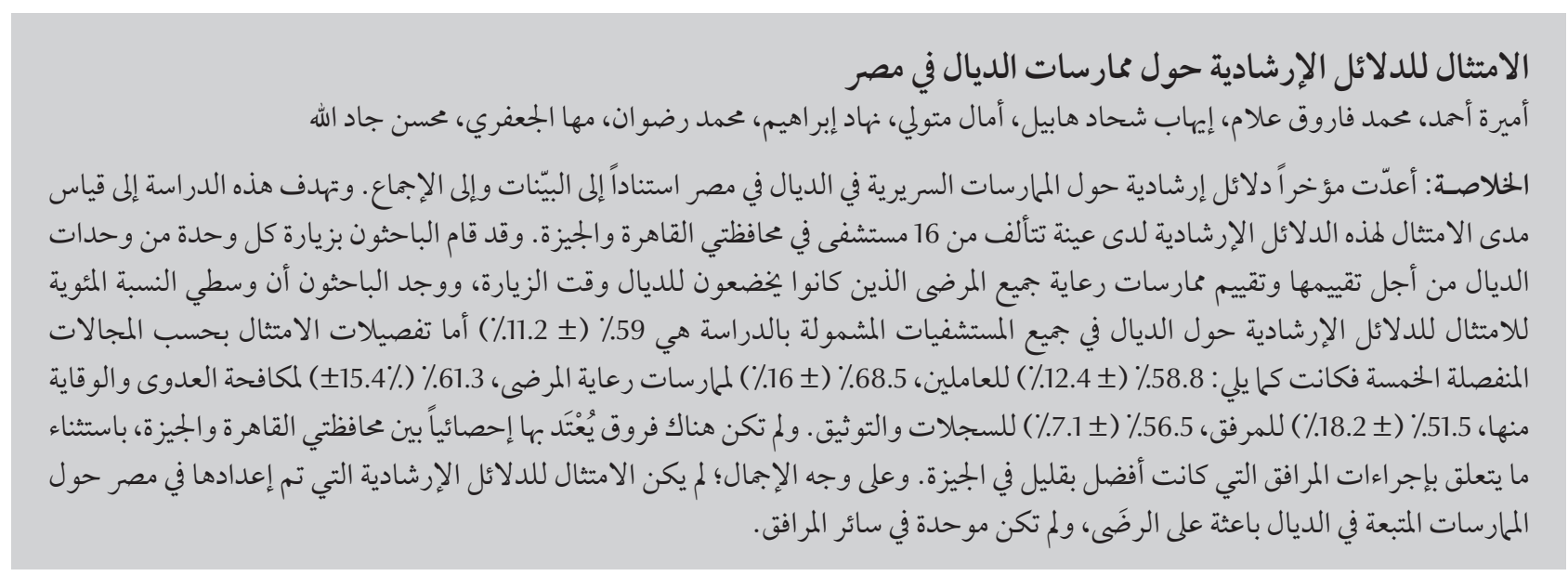

ABSTRACT Evidence- and consensus-based clinical practice guidelines for haemodialysis have recently been developed in Egypt. This study aimed to measure compliance with the guidelines in a sample of 16 government hospitals in Cairo and Giza governorates. Each haemodialysis unit was visited to assess the haemodialysis unit and patient care practices for all patients under dialysis at the time of the visit. The mean percentage compliance with haemodialysis guidelines among all study hospitals was 59.3\% (SD 11.2\%) overall. Within the 5 separate domains, compliance was: 58.8\% (SD 12.4\%) for personnel, 68.5\% (SD 16.0\%) for patient care practices, $61.3 \%$ (SD 15.4\%) for infection prevention and control, 51.5\% (SD 18.2\%) for the facility and 56.5\% (SD 7.1\%) for documentation/ records. There were no statistically significant differences between Cairo and Giza governorates except for facility measures which were slightly better in Giza. Overall, compliance with the developed practice guidelines for haemodialysis in Egypt was not satisfactory and was not uniform across facilities.

\section{Respect des lignes directrices sur les pratiques d'hémodialyse en Égypte}

RÉSUMÉ Des lignes directrices consensuelles et fondées sur des bases factuelles traitant des pratiques d'hémodialyse ont récemment été mises au point en Égypte. L'étude visait à mesurer le respect de ces lignes directrices dans un échantillon de 16 hôpitaux publics des gouvernorats du Caire et de Giza. Chaque service d'hémodialyse a été visité pour être évalué et pour évaluer les pratiques de soins destinés à tous les patients sous dialyse au moment de la visite. Le pourcentage moyen global par le respect des lignes directrices sur les pratiques d'hémodialyse dans l'ensemble des hôpitaux participant à l'étude était de $59,3 \%$ (ET 11,2\%). Plus précisément, dans les cinq domaines évalués, le respect des lignes directrices était de 58,8\% (ET 12,4\%) pour le personnel, 68,5\% (ET 16,0\%) pour les pratiques de soins aux patients, $61,3 \%$ (ET 15,4 \%) pour la prévention et la lutte contre les infections, 51,5\% (ET 18,2\%) pour l'établissement et $56,5 \%$ (ET 7,1\%) pour la documentation/les dossiers. Aucune différence statistiquement significative n'a été observée entre les gouvernorats du Caire et de Giza, sauf pour les mesures concernant les établissements qui étaient légèrement meilleures à Giza. Globalement, le respect des lignes directrices élaborées sur les pratiques d'hémodialyse en Égypte n'était ni satisfaisant ni homogène entre les établissements.

${ }^{7}$ National Research Centre, Cairo, Egypt.

${ }^{2}$ Department of Community, Environmental and Occupational Medicine, Faculty of Medicine, Ain Shams University, Cairo, Egypt (Correspondence to M.F.Allam:fm2faahm@uco.es).

Received: 29/08/11; accepted: 11/01/12 


\section{Introduction}

Health care facilities are seeking nowadays to develop practice guidelines for improving health care services. In the health care sector in Egypt, trials for establishing guidelines have been led by the Ministry of Health and Population (MOHP) [1]. Recently, practice guidelines for haemodialysis were developed in Egypt. These included 5 main domains: personnel, patient care practices, infection prevention and control, facility and documentation/records [2].

Prior to the distribution of the developed practice guidelines it was necessary to establish current levels of compliance in order to monitor the effectiveness of the guidelines. The aim of this study was to measure baseline compliance with the recently developed evidence- and consensus-based clinical practice guidelines for haemodialysis in Egypt.

\section{Methods}

\section{Study design and setting}

The study was conducted in haemodialysis units of government-affiliated hospitals in Cairo and Giza governorates. It was carried out in 2 phases over 6 months: in phase 1 the practice guidelines and the checklist for verification were preparation; in phase 2 field visits to haemodialysis units were conducted to assess the compliance of these units to the practice guidelines set.

\section{Sample}

\section{Haemodialysis units}

Haemodialysis units in 16 hospitals were selected for the study. In Cairo governorate a total of 7 general hospitals affiliated to the MOHP Directorate of Health Affairs in Cairo were included. In Giza governorate, we included 9 hospitals, some affiliated to the MOHP Directorate of Health Affairs in Giza, plus other hospitals affiliated to the Ministry of Interior, Health Insurance
Organization and Ministry of Higher Education and Scientific Research. Hospitals that were not affiliated to the MOHP were included to have a sample of all types of hospitals in Egypt. In addition, consultants from these hospitals had participated in the development of the Egyptian haemodialysis guidelines [2].

\section{Patients}

All patients attending morning haemodialysis sessions during the study period (6 months) were invited to participate in the study. All patients agreed to participate in the study with participation rate of $100 \%$. We observed 160 patients during their haemodialysis sessions. This sample represented more than one-third (35.2\%) of the total patients $(n=454)$.

For medical records we assessed 160 patients' records. The selection was done by a consecutive non-random technique.

\section{Data collection}

Each haemodialysis unit was visited twice: one visit for assessing the haemodialysis unit and another visit for assessing patient care practices for all patients under dialysis at the time of the visit.

The tools of the compliance assessment study were an observational checklist, with documentation review and analysis, and a face-to-face interview.

\section{Scoring of haemodialysis guidelines}

In phase 1 of the study a description of each practice guideline was written, together with the criteria for its verification. The guidelines checklist comprised 5 domains with items and sub-items covering personnel (6 items); patient care practices (5 items); infection prevention and control (5 items); facility (4 items); and documentation/records (3 items) [2]. Most sub-items were scored yes/no while some sub-items were scored ranging between 0 and
1 (satisfactory $=1$, partially met $=0.5$, not satisfactory $=0$ ). For quantitative measures as in the case of observing 10 patients or revising 10 records, if there were 7 patients or records satisfying the criteria the score was 0.7 . Next the total score of the sub-items was divided by the total number of sub-items $\times 100$ to get the mean percentage compliance for the item. Then the mean percentage of each domain was calculated by adding the mean percentages of each item under this domain and calculating the average. Finally the overall mean percentage compliance of the hospital was calculated by adding the mean percentages of each domain, then calculating the average.

\section{Ethical considerations}

Approvals were obtained from the $\mathrm{MOHP}$ to conduct the field visits in the haemodialysis units. Informed consent was taken to interview staff units. Informed consent was obtained from all patients participating in the study. We also provided the Department of Total Quality at the MOHP with the final haemodialysis practice guidelines that had been approved by the panel and experts, in addition to the final results of assessment of the 16 haemodialysis units and the final recommendations.

\section{Statistical analysis}

First, the following descriptive analysis was done: frequency, percentages, mean and standard deviation (SD). Thereafter, a comparison was done between Cairo and Giza haemodialysis units using Student $t$-test for quantitative variables and Fisher exact test for qualitative variables. Data entry and statistical analysis were done using SPSS, version 11.0. The level of significance was set at $P<0.05$.

\section{Results}

The mean percentage compliance with haemodialysis guidelines among all 


\begin{tabular}{|c|c|c|c|c|c|}
\hline \multirow[t]{2}{*}{ Principal domains } & $\begin{array}{c}\text { All hospitals } \\
\quad(n=16)\end{array}$ & $\begin{array}{l}\text { Cairo } \\
(n=7)\end{array}$ & $\begin{array}{l}\text { Giza } \\
(\boldsymbol{n}=9)\end{array}$ & $t$-test & $P$-value \\
\hline & Mean (SD) & Mean (SD) & Mean (SD) & & \\
\hline Personnel & $58.8(12.4)$ & $56.6(14.9)$ & $60.5(10.6)$ & 0.61 & 0.55 \\
\hline Patient care practice & $68.5(16.0)$ & $57.1(15.4)$ & $77.4(10.1)$ & 0.24 & 0.82 \\
\hline Infection prevention and control & $61.3(15.4)$ & $52.3(18.9)$ & $68.4(7.1)$ & 2.36 & 0.03 \\
\hline Facility & $51.5(18.2)$ & $47.5(22.9)$ & $54.6(14.2)$ & 3.17 & 0.01 \\
\hline Documentation/ records & $56.5(7.1)$ & $56.0(6.8)$ & $56.9(7.7)$ & 0.76 & 0.46 \\
\hline Total (overall) & $59.3(11.2)$ & $53.9(14.3)$ & $63.6(6.1)$ & 1.83 & 0.89 \\
\hline
\end{tabular}

$S D=$ standard deviation

study hospitals was 59.3\% (SD 11.2\%) overall. The highest score for individual domains was for personnel $[68.5 \%$ (SD $16.0 \%)]$ and the lowest for the facility guidelines [51.5\% (SD 18.2\%)] (Table 1). There were no statistical significant differences between overall compliance in Cairo and Giza governorates except for the facility and infection prevention and control domains, for which compliance was significantly better in Giza governorate $(P=0.007)$.

No significant differences were found between Cairo and Giza governorates regarding the sub-items of the personnel guidelines domain (Table 2). The percentage of staff with a current Basic Life Support Certificate ranged from only $0 \%$ to $14.3 \%$, with no statistical significant difference between Cairo and Giza governorates. The mean percentage of families with 1 physician for 8 patients/session were similar in Cairo and Giza (57.1\% and 55.6\% respectively), but highly significantly different for the presence of 1 nurse for 3 patients/session ( $0 \%$ and $77.8 \%$ respectively).

For the patient care domain the highest compliance with the guidelines was $86.7 \%$ (SD 16.1\%) for post-dialysis and the lowest was 36.9\% (SD 7.8\%) for between-dialysis practices. Compliance with the guidelines on writing orders for haemodialysis $(P=0.018)$ and the dialysis process $(P=0.001)$ were significantly better in Giza than in Cairo, while predialysis preparation was significantly better in Cairo than in Giza $(P=0.049)$ (Table 3).

For infection prevention and control guidelines the mean compliance ranged from $78.8 \%$ (SD 16.3\%) for housekeeping and waste management to only $13.7 \%$ (SD 29.7\%) for vaccination of patients (Table 4). There were statistical significant differences between Cairo and Giza governorates for occupational health $(P=0.027)$ and housekeeping and waste management $(P=0.004)$, with Giza governorate facilities demonstrating better compliance.

For sub-items of the facility domain the mean compliance with guidelines was 39.6\% (SD 16.3\%) for administration standards, $75.2 \%$ (SD 17.9\%) for physical standards and $50.0 \%$ (SD 18.26\%) for dialysis treatment area. Table 5 shows that compliance with facility guidelines was better in Giza facilities than in Cairo facilities although only the physical standards sub-item was statically significant $(P$ $=0.039$ ).

The mean compliance for sub-items of documentation/records guidelines for employee records and medical records were 19.8\% (SD 29.0\%) and 63.6\% (SD 16.2\%) respectively, with no significant differences between Cairo and Giza governorates (Table 6).

\begin{tabular}{|c|c|c|c|c|c|}
\hline \multirow[t]{2}{*}{ Personnel guidelines } & \multicolumn{2}{|c|}{$\begin{array}{l}\text { Cairo } \\
(n=7)\end{array}$} & \multicolumn{2}{|c|}{$\begin{array}{c}\text { Giza } \\
(n=9)\end{array}$} & \multirow[t]{2}{*}{$P$-value } \\
\hline & No. & $\%$ & No. & $\%$ & \\
\hline Consultants have current certificate in BLS & 1 & 14.3 & 1 & 11.1 & 0.99 \\
\hline Medical directors have current certificate in BLS & 1 & 14.3 & 1 & 11.1 & 0.99 \\
\hline Nursing supervisors have current certificate in BLS & 1 & 14.3 & 0 & 0.0 & 0.44 \\
\hline Staffing: physician for 8 patients/session & 4 & 57.1 & 5 & 55.6 & 0.99 \\
\hline Staffing: nurse for 3 patients/session & 0 & 0.0 & 7 & 77.8 & 0.003 \\
\hline
\end{tabular}

${ }^{a}$ Fisher exact test.

$B L S=$ basic life support. 


\begin{tabular}{|c|c|c|c|c|c|}
\hline \multirow[t]{2}{*}{ Patient care guidelines } & $\begin{array}{l}\text { All hospitals } \\
\quad(n=16)\end{array}$ & $\begin{array}{l}\text { Cairo } \\
(n=7)\end{array}$ & $\begin{array}{l}\text { Giza } \\
(n=9)\end{array}$ & $t$-test & $P$-value \\
\hline & Mean (SD) & Mean (SD) & Mean (SD) & & \\
\hline Writing orders for haemodialysis & $45.9(12.8)$ & $37.9(8.1)$ & $52.2(12.3)$ & 2.67 & 0.018 \\
\hline Pre-dialysis preparation & $38.1(11.1)$ & $44.2(11.0)$ & $33.3(9.0)$ & 2.10 & 0.049 \\
\hline Dialysis process & $75.0(9.9)$ & $66.3(5.0)$ & $81.7(6.9)$ & 4.94 & 0.001 \\
\hline Post-dialysis & $86.7(16.1)$ & $92.9(6.7)$ & 81.9 (19.9) & 1.38 & 0.154 \\
\hline Between dialysis & $36.9(7.8)$ & $39.0(8.6)$ & $35.3(7.1)$ & 0.92 & 0.375 \\
\hline
\end{tabular}

$S D=$ standard deviation .

\section{Discussion}

Compliance with the developed guidelines was evaluated using an objective tool, which was a pre-designed checklist. However, before reaching conclusions based on the present results, it is necessary to remember that compliance was assessed prior to the distribution of the developed practice guidelines. Thus, these results were baseline assessment for haemodialysis facilities rather than evaluation of adherence to the Egyptian practice guidelines. Another possible limitation related to our results was that the MOHP gave approval to assess the compliance with developed Egyptian haemodialysis practice guidelines in hospitals which had haemodialysis units. It is expected that these hospitals offer betterhealth care services and that independent haemodialysis facilities adhere less to the international guidelines, especially private facilities.

The overall mean percentage of compliance with haemodialysis guidelines was $59.3 \%$, with no statistically significant difference between facilities in Cairo and Giza governorates. This means that our haemodialysis facilities already applied less than two-thirds of the newly developed Egyptian haemodialysis practice guidelines. We expect an improvement in the mean percentage of compliance after we have distributed the developed guidelines.

It is necessary to know the main defective items in each governorate. The overall mean percentage compliance with personnel guidelines was $58.8 \%$, and Cairo and Giza governorates had similar figures. Among the sub-items of the personnel domain, the proportions of consultants, medical directors and nursing supervisors with a current
Basic Life Support Certificate was very poor, ranging from $0 \%$ to $14.3 \%$, with no statistical significant difference between Cairo and Giza governorates. Compliance with other sub-items for personnel were better but still defective, i.e. $<75 \%$ of units. For example, just over half of facilities had 1 physician for 8 patients/ session $(57.1 \%$ and $55.6 \%$ in Cairo and Giza governorates respectively). However, the standard of 3 patients for every 1 working nurse in the haemodialysis facilities was met by $0 \%$ of facilities in Cairo and $77.8 \%$ in Giza. Understaffing can lead to higher rates of nosocomial infections, higher rates of medical staff infections, lower patient satisfaction and poor performance [3]. The shortage in trained nurses within the haemodialysis units is a frequent problem in developed countries as well. In the United States of America, a shortage in practising dialysis nurses was observed in many surveys, and it is predicted that with the

\begin{tabular}{|c|c|c|c|c|c|}
\hline \multirow[t]{2}{*}{ Infection prevention guidelines } & $\begin{array}{l}\text { All hospitals } \\
\quad(n=16)\end{array}$ & $\begin{array}{l}\text { Cairo } \\
(n=7)\end{array}$ & $\begin{array}{c}\text { Giza } \\
(n=9)\end{array}$ & $t$-test & $P$-value \\
\hline & Mean (SD) & Mean (SD) & Mean (SD) & & \\
\hline Vaccination of patients & $13.7(29.7)$ & $0.0(0.0)$ & $24.4(36.8)$ & -1.99 & 0.081 \\
\hline $\begin{array}{l}\text { Occupational health and } \\
\text { immunization }\end{array}$ & $63.7(19.0)$ & $50.6(21.0)$ & $73.8(9.2)$ & 2.73 & 0.027 \\
\hline $\begin{array}{l}\text { General infection prevention } \\
\text { measures }\end{array}$ & $55.6(17.2)$ & $50.1(18.8)$ & $59.8(15.9)$ & 1.12 & 0.280 \\
\hline Reprocessing and sterilization & $53.3(19.9)$ & $44.5(25.8)$ & $60.1(10.9)$ & 1.64 & 0.122 \\
\hline $\begin{array}{l}\text { Housekeeping and waste } \\
\text { management }\end{array}$ & $78.8(16.3)$ & $66.7(16.9)$ & $88.1(7.5)$ & 3.43 & 0.004 \\
\hline
\end{tabular}

$S D=$ standard deviation . 


\begin{tabular}{|c|c|c|c|c|c|}
\hline \multirow[t]{2}{*}{ Facility guidelines } & $\begin{array}{l}\text { All hospitals } \\
\quad(n=16)\end{array}$ & $\begin{array}{l}\text { Cairo } \\
(n=7)\end{array}$ & $\begin{array}{l}\text { Giza } \\
(n=9)\end{array}$ & $t$-test & $P$-value \\
\hline & Mean (SD) & Mean (SD) & Mean (SD) & & \\
\hline Administration standards & $39.6(16.3)$ & $33.1(35.6)$ & $43.7(14.7)$ & 0.20 & 0.842 \\
\hline Physical standards & $75.2(17.9)$ & $65.2(15.2)$ & $83.3(16.2)$ & 2.27 & 0.039 \\
\hline Dialysis treatment area & $50.0(18.3)$ & 46.4 (22.5) & 52.8 (15.0) & 0.68 & 0.509 \\
\hline
\end{tabular}

$S D=$ standard deviation.

increasing rates of end-stage renal disease the shortage of nephrology nurses will be an increasing problem [4].

The mean percentage compliance with haemodialysis guidelines among all study hospitals for patient care practice were $57.1 \%$ and $77.4 \%$ in Cairo and Giza governorates respectively. The patient care practice was better in Giza than in Cairo for writing orders for haemodialysis, predialysis preparation and dialysis process. The subitems writing orders for haemodialysis, predialysis preparation and between dialysis were very defective in both Cairo and Giza governorates, ranging from $33.3 \%$ to $44.2 \%$. In general, there was deficiency in writing orders for predialysis, dialysis and between dialysis preparations. Written procedures are mandatory for accreditation systems [5] and are key items for standardizing, defining duties, overcoming gaps in knowledge and maintaining consistent patient care [6].

In the present study, the mean percentage compliance for infection prevention and control guidelines was $61.3 \%$, with significantly better compliance in Giza than in Cairohaemodialysis facilities. General infection prevention measures were deficient in Cairo and Giza governorates (50.1\% and 59.8\% respectively). Hand-washing between patients, after removal of gloves and after contact with any contaminated objects were not habitually practised by the studied health care workers. Similarly, in a study carried out in a haemodialysis unit in Spain, hand-washing was done in $32 \%$ of cases after patient intervention and in 3\% before patient intervention [7]. Poor adherence to standard precautions for hand-washing has been shown in other studies [8].

Housekeeping and waste management were better in Giza than in Cairo haemodialysis facilities. However the mean rates of compliance with housekeeping and waste management in both governorates were more or less satisfactory ( $88.1 \%$ and $66.7 \%$ respectively). This difference between Cairo and Giza could be explained by haemodialysis facilities in Giza governorate being relatively new compared with haemodialysis facilities in Cairo governorate.

The mean percentage of compliance with haemodialysis guidelines for the facility was only $51.5 \%$ among all study hospitals. Compliance at Giza haemodialysis facilities remained significantly better than at Cairo facilities. Physical standards in Giza haemodialysis facilities were far better than physical standards in Cairo haemodialysis facilities. The mean percentage of compliance with facility guidelines in Giza was 83.3\% compared with $65.2 \%$ in Cairo. This could be attributed, as previously mentioned, to the relatively new buildings in Giza governorate.

The documentation/records item in the haemodialysis units was deficient, with a mean percentage compliance less than $57 \%$. Although a bad documentation/records structure may be encountered in many health facilities, it is one of the privileged zones of a quality system [9]. All standards for the documentation/records item were poor. The records were incomplete in most of the cases. This may be due to the multiple data to be filled in the record together with the shortage of the nurses or person in charge to complete these records. One solution could be implementing a computer system in a busy dialysis unit to be used as the primary recording instrument [10]. Another possible solution is developing a simple record format for only the important data [11].

\begin{tabular}{|c|c|c|c|c|c|}
\hline \multirow[t]{2}{*}{ Records guidelines } & $\begin{array}{l}\text { All hospitals } \\
\quad(n=16)\end{array}$ & $\begin{array}{l}\text { Cairo } \\
(n=7)\end{array}$ & $\begin{array}{l}\text { Giza } \\
(n=9)\end{array}$ & $t$-test & $P$-value \\
\hline & Mean (SD) & Mean (SD) & Mean (SD) & & \\
\hline Employee records & $19.8(29.0)$ & $19.0(37.8)$ & $20.4(22.5)$ & 0.09 & 0.932 \\
\hline Medical records & $63.6(16.2)$ & $58.3(19.5)$ & $67.7(12.7)$ & 1.17 & 0.263 \\
\hline
\end{tabular}

$S D=$ standard deviation. 
In conclusion, overall compliance with the developed practice guidelines for haemodialysis in Egypt was defective. Also ofnote, compliance was not uniform across the haemodialysis facilities and this was especially prominent comparing Giza and Cairo governorates for some sub-items. This denotes an unsystematic approach in the Egyptian haemodialysis units and variability in adoption of evidence-based guidelines between facilities affiliated to the MOHP.

The formulated practice guidelines for haemodialysis should be distributed to all haemodialysis facilities in Egypt. Organizing workshops for haemodialysis consultants and directors of haemodialysis facilities to orient them with all items of the developed practice guidelines is necessary. Attendants should be from both public and private sectors.

\section{Acknowledgements}

This project was funded by a grant from EMRO/WHO (RPC TSA 05/8). The development of the Egyptian Haemodialysis Practice Guidelines is the product of a collaborative project between the National Training Institute (Egyptian Ministry of Health and Population) and the Eastern Mediterranean Regional Office (World Health Organization).

We give sincere thanks to all the members of the research team for their willing cooperation in this national project:

Development of checklist: Dr Amira Mohsen Gadallah, National Training Institute, Dr Ehab Shehad, Ain Shams University, Dr Mohamed Farouk Allam, National Training
Institute/Ain Shams University and Professor Dr Mohsen Gadallah, National Training Institute/Ain Shams University.

Field visits: Dr Ahmed Wasfy, National Training Institute, Dr Amira Mohsen Gadallah, National Training Institute, Dr Ehab Shehad, Ain Shams University, Dr Milad Ismail AboBakr, Directorate of Cairo Health Affairs, Professor Dr Mohsen Gadallah, National Training Institute/Ain Shams University, Dr Salah Abd El-Ghaffar, Directorate of Giza Health Affairs.

Data management: Dr Amira Mohsen Gadallah, National Training Institute, Dr Mohamed Farouk Allam, National Training Institute/Ain Shams University, Professor Dr Mohsen Gadallah, National Training Institute/ Ain Shams University

\section{References}

1. Quality assurance manual for primary health care services, 2nd ed. Cairo, Ministry of Health and Population, 1999.

2. Ahmed AM et al. Development of practice guidelines for hemodialysis in Egypt. Indian Journal of Nephrology, 2010, 20:193-202.

3. Bolton WK. Nephrology nurse practitioners in a collaborative care model. American Journal of Kidney Diseases, 1998, 31:786-793.

4. Bednar B, Steinman TI, Street J. Changing the operating structure. Nephrology News and Issues, 2002, 16:25-28.

5. Report on the Expert Group Meeting on Hospital Accreditation. Cairo, World Health Organization Regional Office for the Eastern Mediterranean, 2003.

6. Zimmerman JF. The importance of standard operating procedure for investigators. SoCRA Source, November 1999 (http:// www.impactcg.com/docs/SOCRA_11.99_SOPs.pdf, accessed 12 October 2012).
7. Jimenez DA et al. Audit on the degrees of application of universal precautions in a haemodialysis unit. Nephrology, Dialysis, Transplantation, 1999, 14:1001-1003.

8. Doebbeling BN, Stanley GL, Sheetz ZT. Comparative efficacy of alternative hand washing agents in reducing nosocomial infections in intensive care units. New England Journal of Medicine, 1992, 327:88-93.

9. Hermelin A et al. Quality management in the hospital environment: ISO 9002 certification: our experience. Nephrologie, 2002, 23:7-10.

10. Ash SR et al. Evolution of the medical record format during two years' use of an open-format microcomputer charting system. Journal of Clinical Engineering, 1991, 16:337-348.

11. Hendrickson G, Kovner CT. Effects of computers on nursing resource use. Do computers save nurses time? Computers in Nursing, 1990, 8:16-22. 